Received 28 June 2021 Accepted 18 August 2021

Link to DOI:

10.25220/WNJ.V04.i2.0006

Journal Website: www.worldnutrijournal.org

\section{Energy target achievement and its determinants in critically ill COVID-19 patients in Indonesia}

Niken Puruhita ${ }^{1}$, Febe Christianto ${ }^{2}$, Luciana B Sutanto ${ }^{3}$, Banundari Rachmawati ${ }^{1}$, Sofyan Harahap ${ }^{4}$, Muchlis Achsan Udji Sofro ${ }^{4}$, Retnaningsih ${ }^{4}$, I Riwanto ${ }^{5}$, Hertanto Wahyu Subagio ${ }^{1}$

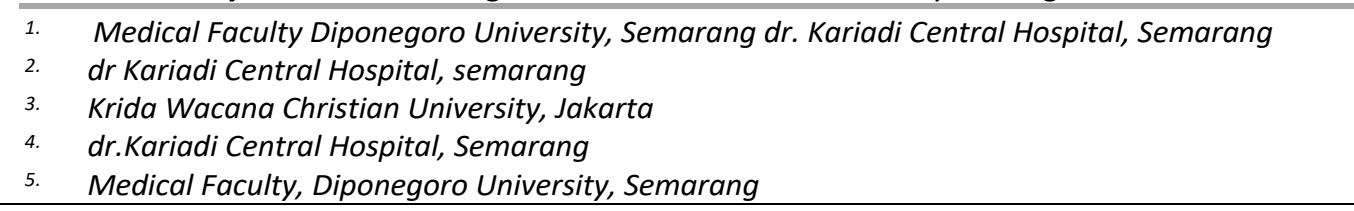

\begin{abstract}
Introduction. Achievement of energy target in critically ill Covid-19 patients in Intensive Care Unit (ICU) is challenging. This study was aimed to depict the possibility of achieving energy target and its determinants in critically ill Covid-19 patients.

Methods. A cross sectional study was conducted in ICU of dr. Kariadi Hospital Semarang, Indonesia. Secondary data were obtained from Covid-19 patients who were in ICU for minimum 3 days, from March to December 2020. Data collected included age, sex, Body Mass Index (BMI), comorbidities, Modified Nutrition Risk in Critically III (mNUTRIC) score, energy intake, route of nutrition delivery (enteral or combination of enteral and parenteral nutrition), lactate status, ICU length of stay (LOS), duration of mechanical ventilator and mortality. Risk Prevalence calculations were conducted to measure risks. Variables with significant associations and $p<0.25$ were included in multiple logistic regression.

Results. A total of 188 subjects were included in the analysis. Most patients were male (62.8\%) and obese (61.8\%). As much as $56.9 \%$ patients were able to achieve energy target of $20 \mathrm{kcal} / \mathrm{kgBW}$ on day 3 of ICU stay. Those with low risk mNUTRIC score and nutrition delivery was through enteral and parenteral route were more likely to achieve target energy of $20 \mathrm{kcal} / \mathrm{kgBW}$ in the first 3 days in the ICU.

Conclusions. Achieving energy target of $20 \mathrm{kcal}$ on day 3 of ICU stay for critically ill Covid-19 patients is feasible. Low mNutric score and nutrition delivery through enteral and parenteral route were two determinants for the achievement.
\end{abstract}

Keywords energy target in ICU, mNutric score, early nutrition in ICU, Covid-19 


\section{Introduction}

Achievement of energy target during the first week of ICU stay is mandatory for better outcome. Several factors determine the achievement, putting unstable hemodynamic and gastrointestinal intolerance as pitfalls in reaching energy target. Factors associated with hemodynamic such as vasopressor dose, lactate level, the use of mechanical ventilator may affect energy intake. Other factors such as age, comorbidities may also contribute to failure of energy intake achievement. Nutritional screening tool for ICU patients, Nutric score, often shows association with ICU outcome.

Feeding patients with vasopressor is possible. Previous study reported in critically ill patients with vasopressor, enteral feeding can be started when the dose is low-medium or decreased by time. ${ }^{1}$ High lactate level indicates the presence of splanchnic hypoperfusion and thus feeding intolerance. ${ }^{2}$ The use of mechanical ventilator indicates perfusion problems and may lead to disruption of feeding. ${ }^{3}$

Route of nutrition administration determine the success of energy target achievement. In nonintubated critically ill Covid-19 patients, semi solid oral diet may be administered. Oral Nutrition Supplement (ONS) was advised for those who cannot obtain energy target due to shortness of breath. Patients with High Flow Nasal Canule (HFNC) need to be assessed and monitored closely for fulfillment of energy and nutrients target from oral intake. Tube feeding or ONS can be initiated for patients with HFNC when chewing foods caused dyspnea. Early enteral nutrition is also recommended for patients who proceed to mechanical ventilation. When all measures have been conducted and energy intake remains inadequate, early parenteral nutrition is acceptable for any critically ill covid- 19 patients. ${ }^{4}$

The amount of enteral nutrition administered for critically ill covid-19 patients is of interest. Energy need in the ICU is suggested to be determined by using indirect calorimetry. In hospitals where indirect calorimetry is unavailable, prediction equation may be used. During early period, ESPEN recommended energy supply to start with $20 \mathrm{kcal} / \mathrm{kg}$ $\mathrm{BW} /$ day, increased to $50-70 \%$ in the following day and reached $80-100 \%$ predictive energy at fourth day of ICU stay. ${ }^{4}$ A recent study measured REE in
22 intubated covid-19 patients reported that median REE of patients were $19 \mathrm{kcal} / \mathrm{kg}$ actual BW in first week of ICU stay. These numbers were slightly lower in obese patients either using actual or adjusted body weight measurement. ${ }^{5}$ Another expert recommended a steeply increased energy prescription from $10 \mathrm{kcal} / \mathrm{kgBW}$ on the first day, 15 $\mathrm{kcal} / \mathrm{kgBW}$ on the second day and $20 \mathrm{kcal} / \mathrm{kgBW}$ on the third day. ${ }^{6}$

Regardless the increasing number of available guidelines for ICU Covid-19 patients, there have been limited studies which depicted application of nutrition therapy for these patients. This study was aimed to measure risk factors for energy target achievement in critically ill Covid-19 patients in Indonesia.

\section{Methods}

\section{Study design and subjects}

A cross sectional study was conducted in the ICU dedicated for Covid-19 patients in dr. Kariadi General Hospital, Semarang, Indonesia. Inclusion criteria were all confirmed Covid-19 patients who were in ICU for 3 days or more from March to December 2020. Exclusion criteria were patients with unstable hemodynamic or massive upper gastrointestinal bleeding.

\section{Data collection and definitions}

Data collected secondarily from e-medical record. Data obtained included characteristics of subjects such as age, sex, BMI, ICU length of stay (LOS) and mortality. Data for age and sex were obtained from patients' ID card. BMI (Quetelet index) of patients was calculated using formula Weight $(\mathrm{kg}) / \mathrm{height}^{2}\left(\mathrm{~m}^{2}\right)$. ICU LOS was calculated from ICU admission until patients died or were allowed to be transferred to ward. Mortality was recorded as whether a patient transferred alive or died at the end of ICU stay. Other data collected for analysis were energy intake, route of intake, comorbidities, mNUTRIC score, dosage of vasopressor, the use of mechanical ventilator, lactate level.

Dependent variable was the achievement of energy target which was defined as whether a patient 
achieved energy intake of $20 \mathrm{kcal}$ on day 3 of ICU stay. This target based on a guideline for energy requirements of critically ill Covid-19 patient during early period in the ICU. ${ }^{6}$

Independent variables included route of intake, comorbidities, mNUTRIC score, dosage of vasopressor, the use of mechanical ventilator and lactate level. Route of intake was divided into enteral nutrition only and combination of enteral and parenteral nutrition. Comorbidities was defined as the presence of minimal 1 comorbidity at the time of admission, either reported by family or from previous medical record. mNUTRIC scores were calculated during the first 48 hours of ICU admission. Dosage of vasopressor was the maximum dose used during the period of ICU stay. It was categorized high when norepinephrine dose was more than $0.3 \mathrm{mcg} / \mathrm{kgBW}$ or combination with other vasopressors such as dobutamine and vasopressin. Vasopressor dose was categorized as low if only norepinephrine was used and with dose $0.3 \mathrm{mcg} / \mathrm{kgBW}$ or lower. ${ }^{1}$ Use of mechanical ventilator was recorded as the number of days a patient was on mechanical ventilator during ICU stay. Lactate level that was measured in the first 3 day was used as variable in this study. It was categorized as more or less than $4 \mathrm{mg} / \mathrm{L}$.

\section{Statistical analysis}

Data analysis was performed in SPSS 11 program. Nominal data were presented as frequencies while numeric data were presented as mean and standard deviation (SD) or median and interquartile range (IQR). Risk Prevalence was calculated for each independent variable. Further analyzed using multiple logistic regression to seek significant risk factors. Ethical Clearance has been obtained from Health Research Ethics Committee of RSUP dr.Kariadi Semarang no.531/EC/KEPKRSDK/2020. Informed consent was not obtained as this was a retrospective study using secondary data from e-medical record.

\section{Results}

A total number of 188 eligible subjects out of 191 patients who were admitted to ICU from March to December 2020 were included in the analysis.
Table 1 depicted characteristics of our subjects, which showed that more than $30 \%$ subjects were elderly. Our patients were mostly male $(62,8 \%)$ and obese $(61.8 \%)$. A small number of subjects were undernourished based on BMI. Type 2 Diabetes Mellitus and hypertension were the two most frequent comorbidities observed in our subjects, followed by cardiovascular/ cerebrovascular diseases and chronic kidney disease. A small proportion of subject were pregnant women with hypertension and pre-eclampsia/eclampsia. According to mNutric score which was calculated in the first 24 hour of ICU admission, only $15 \%$ of our patients were admitted to ICU with high nutritional risk. Most of our patients were reported to have short period of symptoms before hospital admission and thus, a relatively fair condition at the point of admission.

More than $50 \%$ subjects were on mechanical ventilator and the rest were using HFNC. Few subjects wore non-rebreathing mask for a short period of time before putting on HFNC or being intubated. Most patients required mechanical ventilator in the first 5 days in the ICU, with the median of mechanical ventilator day length was 5 days (IQR 3 - 9). The longest duration of mechanical ventilator was 29 days. Median of ICU LOS was 8 days (IQR 4 - 11) with the maximum stay was 46 days. The mortality rate was as high as $53.7 \%$, mostly those with mechanical ventilator $(85.4 \%)$, elderly $(60 \%)$ and undernourished based on BMI (100\%).

In terms of energy target, more than $50 \%$ of subjects reached $20 \mathrm{kcal} / \mathrm{kg} \mathrm{BW} /$ day during the first 3 days in the ICU. More than $80 \%$ of our subjects received enteral nutrition started on day 1 in the ICU and more that $90 \%$ received enteral nutrition during three days of ICU stay. About $60 \%$ of our subjects were prescribed supplemental parenteral nutrition in whom $50 \%$ of them received it during the first 3 days of their ICU stay.

Several factors associated with energy target achievement of $20 \mathrm{kcal}$ on day 3 were observed and analyzed. Age, sex, the presence of comorbidities and dosage of vasopressor were not risk factors for achievement of energy target. Meanwhile, risk prevalence calculation suggested that patients who had low risk of malnutrition based on mNutric score, were not on mechanical ventilator, had lactate level 
less than $4 \mathrm{mmol} / \mathrm{L}$ and had both enteral and parenteral nutrition as route of delivery were more likely to achieve energy target of $20 \mathrm{kcal}$ on day 3 (Table 2).

Putting together, when a multiple logistic regression was performed, only mNUTRIC score group and route of nutrition administration became significant determinants (Table 3). Patients with low nutritional risk based on mNUTRIC score was 8.7 times more likely to achieved $20 \mathrm{kcal} / \mathrm{kg} \mathrm{BW}$ at day 3. Similarly, patients receiving nutrition from both enteral and parenteral route, was 8.5 times more likely to reach $20 \mathrm{kcal} / \mathrm{kgBW}$ on day 3 .

\section{Discussion}

Most of subjects were male and obese. This result is in accordance with other study in Indonesia which also observed a higher prevalence in these group of patients with Covid-19.7 A meta-analysis of 75 worldwide studies reported that obese people have higher risks for being Covid-19 positive, hospitalization, ICU admission and mortality. ${ }^{8}$ The prevalence of Covid-19 patients with BMI $\geq$ $30 \mathrm{~kg} / \mathrm{m}^{2}$ in our study was lower compared to French studies which reported the range prevalence of $25 \%$ to $47 \% .^{9,10}$ Being obese put a person in higher susceptibility for some infectious disease such as influenza and nosocomial infection. ${ }^{11}$ The link between obesity and Covid-19 infection may be explained through several mechanisms such as adipose inflammation, impaired immunity and comorbidities found in obese people such as hypertension and type 2 diabetes mellitus. ${ }^{8}$

Elderly patients comprised about one third of our subjects. This high proportion may be due to poor immunity states among older people. Higher prevalence of elderly with Covid-19 was also found in a study conducted in Indonesia's National General Hospital. ${ }^{12}$ However, the prevalence of older people with Covid-19 in our study much higher compared to study conducted in Wuhan which reported the prevalence of $11.5 \% .{ }^{13}$

Most prevalent comorbidities observed in our study were type 2 diabetes mellitus and hypertension. These findings were similar with study which were conducted in $\mathrm{China}^{14}$ and Indonesia. ${ }^{7}$ It suggested the role of ACE2 in the pathogenesis of Covid-19 infection. ${ }^{15,16}$ These two comorbidities frequently occurs in obese people, suggesting metabolic dysfunction in these population. ${ }^{8}$

The prevalence of high mNUTRIC score was low in our study compared to other study findings. This may be due to different characteristics of study subjects across countries. Two studies in China reported thatqa mNUTRIC score was applicable to determine nutrition risk and mortality in critically ill Covid-19 patients. ${ }^{17,18}$

ICU LOS and VM length observed in our study were somewhat shorter compared to previous metaanalysis from 7 studies which reported duration of ICU stay and being ventilated of 7.8 and 10.1 days respectively. ${ }^{19}$ These differences might be due to higher mortality in our study subjects in the ICU and those with MV compared to findings from the metaanalysis. Various mortality rates in critically ill Covid-19 have been widely published. Compared to our study, the ICU mortality rate of previous studies were similar, but, the proportion of deceased patients who were on mechanical ventilator in other studies were significantly lower..$^{20,21}$ Meanwhile, a meta-analysis from 28 studies from 7 countries found mortality rate of $28.3 \%$ and $43 \%$ of those who were in ICU and being in mechanical ventilator respectively. Mechanical ventilator usage was found to be the major predictor for mortality. ${ }^{19}$

Our study found that more than $80 \%$ of our patients tolerated small dose EN on day 1 in ICU (median $11.7 \mathrm{kcal} / \mathrm{kg}$ BW, IQR 8.4 - 15.1). A retrospective cohort study in critically ill Covid-19 patients reported that early enteral nutrition was feasible and safe for this group of patients during the first week of ICU stays. ${ }^{22}$ Another retrospective study in critically ill Covid-19 patients receiving mechanical ventilator revealed that administration of EN in the first 24 hour of mechanical ventilation did no harm to the patients. ${ }^{23}$ Our study also found that combining EN with PN made achievement of energy target of day 3 in ICU is possible. This was in concordance with a meta-analysis by Luo which reported that administration of combined PN and EN was reported to have no difference with EN only in terms of mortality, infection, nutrition related complication, ventilatory support or C-reactive protein (CRP). ${ }^{24}$

This study found that obtaining energy target of $20 \mathrm{kcal} / \mathrm{kg} \mathrm{BW}$ in day 3 of ICU stay was possible. A 
small retrospective study conducted in severe and critically ill Covid-19 patients in China reported that permissive under feeding is feasible in critically ill Covid-19 patients. ${ }^{25}$ Interestingly, the LEEP Covid study reported that measured REE in critically ill Covid-19 patients were at the range of 15-20 $\mathrm{kcal} / \mathrm{kgBW}$ during the first week, therefore, our study result was in line with LEEP Covid study. ${ }^{5}$

Bivariate analysis found that variables which significantly associated with energy target achievement of $20 \mathrm{kcal} / \mathrm{kgBW}$ were mNUTRIC score, the use of mechanical ventilator, lactate level and route of nutrition were. Risk prevalence for these variables indicated that in critically ill Covid19 patients who had low mNutric score, were not on mechanical ventilator, had lactate level less than 4 $\mathrm{mmol} / \mathrm{L}$ and received nutrition from both enteral and parenteral route were more likely reaching energy target of $20 \mathrm{kcal} / \mathrm{kgBW}$ on day 3 . This may be explained that those patients were hemodynamically stable, less severe disease, and/or less complications, which may lead to disruption of nutrition delivery. Multiple logistic regression revealed that only mNUTRIC score group and route of nutrition administration became significant predictors. The plausible explanation for this finding was that low nutrition risk based on mNutric score indicated patients were in less severe ARDS and hemodynamically stable which made the delivery of nutrition was possible. The previous retrospective study in critically ill Covid-19 patients on mechanical ventilator also found that main reason for interruptions of enteral nutrition during the first week were hemodynamic instability and GI intolerance. 22 When an enteral route was used without any supplemental PN, it seemed that disruption of enteral feeding due to gastrointestinal intolerance/bleeding, unstable hemodynamic and fasting related procedure led to failure of energy target achievement at day 3. Adding supplemental parenteral nutrition seems feasible and safe for our subjects. A systematic review and meta-analysis comparing EN and combined EN with supplemental PN revealed that the later increasing energy intake without increasing ICU mortality and length of stay. ${ }^{26}$

Wrapping up, most of our subjects are male and obese, with two third of them are elderly. The ICU mortality rate is quite high. Our study confirms that achieving energy target of $20 \mathrm{kcal} / \mathrm{kgBW}$ during the first 3 days of ICU stay for critically ill Covid 19 patients is possible. Two determinants for the achievement of energy target are mNUTRIC score and the route of nutrition delivery. Further study confirming other factors such as renal and liver functions which may influence the achievement energy target may be needed. 
Table 1. Characteristics of subjects

\begin{tabular}{|c|c|c|}
\hline Characteristics & Mean \pm SD & n (\%) \\
\hline Age (years old) & $53.7 \pm 12.67$ & \\
\hline$\geq 65$ & & $62(33.0)$ \\
\hline$<65$ & & $126(67.0)$ \\
\hline \multicolumn{3}{|l|}{ Sex } \\
\hline Male & & $118(62.8)$ \\
\hline Female & & $70(37.2)$ \\
\hline \multicolumn{3}{|l|}{ Nutritional status (BMI, Asia Pacific Criteria) } \\
\hline Underweight $\left(<18.5 \mathrm{~kg} / \mathrm{m}^{2}\right)$ & & $4(2.1)$ \\
\hline Normoweight $\left(18.5-22.9 \mathrm{~kg} / \mathrm{m}^{2}\right)$ & & $37(19.6)$ \\
\hline Overweight $\left(23.0-24.9 \mathrm{~kg} / \mathrm{m}^{2}\right)$ & & $31(16.5)$ \\
\hline Obese Grade I $\left(25.0\right.$ - $\left.29.9 \mathrm{~kg} / \mathrm{m}^{2}\right)$ & & $84(44.7)$ \\
\hline Obese Grade II $\left(30.0-34.9 \mathrm{~kg} / \mathrm{m}^{2}\right)$ & & $24(12.8)$ \\
\hline Obese Grade III/Morbid Obese (> 35 kg/m²) & & $8(4.3)$ \\
\hline \multicolumn{3}{|l|}{ Comorbidities (excluding obesity) } \\
\hline DM without or with complication & & $66(37.5)$ \\
\hline Hypertension & & $61(34.7)$ \\
\hline Cardiovascular/cerebrovascular disease & & $35(19.9)$ \\
\hline Chronic kidney disease & & $26(14.8)$ \\
\hline No reported or observed comorbidities & & $60(31.8)$ \\
\hline \multicolumn{3}{|l|}{ mNUTRIC Score } \\
\hline High risk & & $18(15.5)$ \\
\hline Low risk & & $98(84.5)$ \\
\hline Patients on VM & & $106(56.4)$ \\
\hline VM length (days) & $6,8 \pm 5.46$ & \\
\hline ICU LOS (days) & $8.8 \pm 6.83$ & \\
\hline \multicolumn{3}{|l|}{ ICU discharge status } \\
\hline Deceased & & $101(53.7)$ \\
\hline Alive & & $87(46.3)$ \\
\hline \multicolumn{3}{|l|}{ Achieved $20 \mathrm{kcal} / \mathrm{kg} \mathrm{BW}$ at day 3} \\
\hline Yes & & $107(56.9)$ \\
\hline No & & $81(43.1)$ \\
\hline Proportion of subjects received EN for the first 3 days in ICU & & $178(96.7)$ \\
\hline Proportion of subject received PN for the first 3 days in ICU & & $60(51.7)$ \\
\hline
\end{tabular}


Table 2. Risk factors for achievement of energy target

\begin{tabular}{|c|c|c|c|c|}
\hline \multicolumn{2}{|c|}{$\begin{array}{l}\text { Achievement of } 20 \text { kcal } \\
\text { at day } 3\end{array}$} & \multirow{2}{*}{$\begin{array}{l}\text { No } \\
\mathbf{n}(\%)\end{array}$} & \multirow{2}{*}{$\begin{array}{l}\text { Yes } \\
\mathbf{n}(\%) \\
\end{array}$} & \multirow[t]{2}{*}{$\begin{array}{c}\text { RP } \\
(95 \% \mathrm{CI})\end{array}$} \\
\hline & & & & \\
\hline \multirow{2}{*}{ Age (year) } & $\geq 65$ & $12(16.2)$ & $22(21.6)$ & $0.74(0.33-1.53)$ \\
\hline & $<65$ & $62(83.8)$ & $80(78.4)$ & \\
\hline \multirow[t]{2}{*}{ Sex } & Male & $49(59.8)$ & $70(64.8)$ & $0.93(0.51-1.74)$ \\
\hline & Female & $33(40.2)$ & $38(35.2)$ & \\
\hline \multirow[t]{2}{*}{ Comorbidity } & Yes & $57(69.5)$ & $70(64.8)$ & $1.06(0.56-2.02)$ \\
\hline & No & $25(30.5)$ & $38(35.2)$ & \\
\hline \multirow[t]{2}{*}{ Vasopressor } & High & $8(22.2)$ & $6(26.1)$ & $0.71(0.21-2.46)$ \\
\hline & Low-medium & $28(77.8)$ & 17(73.9) & \\
\hline \multirow{2}{*}{ m-NUTRIC score } & High risk & $13(28.9)$ & $5(7.0)$ & $5.03(1.63-15.54)$ \\
\hline & Low risk & $32(71.7)$ & $66(93.0)$ & \\
\hline \multirow[t]{2}{*}{ Mechanical Ventilator } & Yes & $66(61.1)$ & $42(38.9)$ & $6.70(3.27-13.74)$ \\
\hline & No & $16(19.5)$ & $66(61.1)$ & \\
\hline \multirow[t]{2}{*}{ Lactate level } & $>4$ & $20(48.8)$ & $11(22.4)$ & $3.18(1.26-8.09)$ \\
\hline & $\leq 4$ & $21(51.2)$ & 38 (77.6) & \\
\hline \multirow[t]{2}{*}{ Route } & EN & $55(77.5)$ & $62(62.0)$ & $2.11(1.06-4.19)$ \\
\hline & $\mathrm{EN}+\mathrm{PN}$ & $16(22.5)$ & $38(38.0)$ & \\
\hline
\end{tabular}

EN: enteral nutrition; PN: parenteral nutrition; RP: risk prevalence

Table 3. Multiple logistic regression models for variables with $\mathrm{p}<0.05$

\begin{tabular}{llll}
\hline & B & p & Risk (95\% CI) \\
\hline m-NUTRIC score & 2.162 & $0.013^{*}$ & $8.7(1.19-32.08)$ \\
Mechanical ventilator & 0.872 & 0.271 & $2.4(0.47-10.6)$ \\
Lactate group & 0.979 & 0.168 & $2.7(0.70-11.65)$ \\
Nutrition route & 2.140 & $0.005^{*}$ & $8.5(2.15-30.23)$ \\
\hline
\end{tabular}

\section{Conflict of Interest}

Authors declared no conflict of interest regarding this article.

\section{Acknowledgement}

Our research team express our gratitude to the physicians, nurses, physiotherapist, pharmacists and other supporting services who have been working hard in an excellent team work for COVID-19 patients in ICU of dr. Kariadi Central General Hospital.

\section{Open Access}

This article is distributed under the terms of the Creative Commons Attribution 4.0 International

\section{Licence}

(http://creativecommons.org/licenses/by/4.0/), which permits unrestricted use, distribution, and reproduction in any medium, provided you give appropriate credit to the original author(s) and the source, provide a link to the Creative Commons license, and indicate if changes were made.

\section{References}

1. Wischmeyer PE. Enteral Nutrition Can Be Given to Patients on Vasopressors. Crit Care Med 2020; 48: 122125.

2. Mao Z, Liu G, Yu Q, Qi S, Lou Y, Liu C et al. Association between serum lactate levels and enteral feeding intolerance in septic patients treated with vasopressors: a retrospective cohort study. Ann Transl Med 2020; 8: 1240-1248. doi: http://dx.doi.org/10.21037/atm-20-6317 
3. Chen W, Du M, Chen Y, Yuan D. Factors influencing feeding intolerance in critically ill patients during enteral nutrition. Int J Clin Exp Med 2019; 12: 79998003 .

4. Barazzoni R, Bischoff SC, Breda J, Wickramasinghe K, Krznaric Z, Nitzan D et al. ESPEN expert statements and practical guidance for nutritional management of individuals with SARS-CoV-2 infection. Clin Nutr 2020; 39: 1631-1638. doi: https://doi.org/10.1016/j.clnu.2020.03.022

5. Whittle $\mathrm{J}$, Molinger $\mathrm{J}$, MacLeod D, Haines $\mathrm{K}$, Wischmeyer P. Persistent hypermetabolism and longitudinal energy expenditure in critically ill patients with COVID-19. Crit Care 2020; 24: 581-584. doi: https://doi.org/10.1186/s13054-020-03286-7

6. Thibault R, Seguin P, Tamion F, Pichard C, Pierre Singer. Nutrition of the COVID-19 patient in the intensive care unit (ICU): a practical guidance. Crit Care 2020; 24: 447-414. doi: https://doi.org/10.1186/s13054-020-03159-z

7. Karyono DR, Wicaksana AL. Current Prevalence, Characteristics, and Comorbidities of Patients with Covid-19 in Indonesia. Journal of Community Empowerment for Health 2020; 3: 77-84. doi: 10.22146/jcoemph.57325

8. Popkin BM, Du S, Green WD, MA. B, Algaith T, Herbst $\mathrm{CH}$ et al. Individuals with obesity and COVID19: A global perspective on the epidemiology and biological relationships. Obesity Reviews 2020; 21: e13128-13139. doi: https://doi.org/10.1111/obr.13128

9. Caussy C, Pattou F, Wallet F, Simon C, Chalopin S, Telliam C et al. Prevalence of obesity among adult inpatients with COVID-19 in France. www.thelancet.com/diabetes-endocrinology 2020; 8: 562-564. doi: https://doi.org/10.1016/S22138587(20)30160-1

10. Simonnet A, Chetboun M, Poissy J, Raverdy V, Noulette J, Duhamel A et al. High prevalence of obesity in severe acute respiratory syndrome coronavirus-2 (SARS-CoV-2) requiring invasive mechanical. Obesity 2020. doi: DOI: $10.1002 /$ oby. 22831

11. Huttunen R, Syrjänen J. Obesity and the risk and outcome of infection. Int J Obes (Lond) 2013; 3: 333340.

12. Azwar MK, Setiati S, Rizka A, Fitriana I, SR S, Safitri E. Clinical Profile of Elderly Patients with Covid-19 Hospitalized in Indonesia's National General Hospital. Acta Med Indones - Indones J Intern Med 2020; 52: 199-205.

13. Guo Y, Liu X, Deng M, Liu P, Li F, Xie N et al. Epidemiology of COVID-19 in older persons, Wuhan, China Age and Ageing 2020; 49: 706-712. doi: https://doi.org/10.1093/ageing/afaa145

14. Wang D, Hu B, Hu C, Zhu F, Liu X, Zhang J et al. Clinical characteristics of 138 hospitalized patients with 2019 novel coronavirus-infected pneumonia in Wuhan, China. JAMA 2020; 323: 1061-1069.

15. Ni W, Yang X, Yang D, Bao J, Li R, Xiao Y et al. Role of Angiotensin Converting Enzyme 2 (ACE2) in
COVID-19. Crit Care 2020; 24: 422-431. doi: http://doi.org/10.1186/s13054-020-03120-0

16. Bornstein SR, Dalan R, Hopkins D, Mingrone G, BO B. Endocrine and Metabolic Link to Coronavirus Infection. Nat Rev Endocrinol 2020; 2: 1-2. doi: https://doi.org/10.1038/s41574-020-0353-9

17. Zhang P, He Z, Yu G, Peng D, Feng Y, Ling J et al. The modified NUTRIC score can be used for nutritional risk assessment as well as prognosis prediction in critically ill COVID-19 patients. 2020. doi: https://doi.org/10.1016/j.clnu.2020.05.051

18. Li G, Zhou C, Ba Y, Wang Y, Song B, Cheng X et al. Nutritional risk and therapy for severe and critical COVID-19 patients: A multicenter retrospective observational study. Clinical Nutrition. doi: https://doi.org/10.1016/j.clnu.2020.09.040

19. Chang R, Elhusseiny KM, Yeh Y, Sun W. COVID-19 ICU and mechanical ventilation patient characteristics and outcomes - A systematic review and meta-analysis. PLoS ONE 2021; 16(2): e0246318. doi: https://doi.org/10.1371/journal.pone.0246318

20. Auld SC, Caridi-Scheible M, Blum JM, Robichaux C, Kraft C, Jacob JT et al. ICU and Ventilator Mortality Among Critically Ill Adults With Coronavirus Disease 2019. Crit Care Med 2020; 48: e799-e804.

21. King CS, Sahjwani D, Brown AW, Feroz S, Cameron $\mathrm{P}$, Osborn E et al. Outcomes of mechanically ventilated patients with COVID-19 associated respiratory failure. $P L O S \quad O N E$ 2020; 15: e0242651. doi: https://doi.org/10.1371/journal.pone.0242651

22. I.Osuna-Padilla, N.C.Rodríguez-Moguel, A.AguilarVargas, S.Rodríguez-Llamazares. Safety and tolerance of enteral nutrition in COVID-19 critically ill patients, a retrospective study. Clin Nutr ESPEN 2021. doi: https://doi.org/10.1016/j.clnesp.2021.02.015

23. Farina N, Nordbeck S, Montgomery M, Cordwin L, Blair F, Cherry-Bukowiec J et al. Early Enteral Nutrition in Mechanically Ventilated Patients With COVID-19 Infection. Nutr Clin Pract 2021; 00: 1-9.

24. Luo Y, Qian Y. Effect of combined parenteral and enteral nutrition for patients with a critical illness: A meta-analysis of randomized controlled trials. Medicine 2020; 99: 3(e18778).

25. Yue X, Li M, Wang Y, Zhang J, Wang X, Kan L et al. Nutritional Support and Clinical Outcome of Severe and Critical Patients With COVID-19 Pneumonia. Front. Nutr. 2020; 7: 581679. doi: doi: 10.3389/fnut.2020.581679

26. Alsharif DJ, Alsharif FJ, Aljuraiban GS, Abulmeaty MMA. Effect of Supplemental Parenteral Nutrition Versus Enteral Nutrition Alone on Clinical Outcomes in Critically Ill Adult Patients: A Systematic Review and Meta-Analysis of Randomized Controlled Trials. Nutrients 2020; 12: $2968 . \quad$ doi: doi:10.3390/nu12102968 